\title{
JOB SATISFACTION AMONG DENTISTS OF THE MINISRTY OF HEALTH IN ALEXANDRIA
}

\author{
Eman M. Ghannam ${ }^{1}{ }_{B D s}$, Hala A. Amer ${ }^{2} P h D$, Wafaa E. Abdelaziz ${ }^{2} P h D$
}

\begin{abstract}
INTRODUCTION: High prevalence of work-related physical and psychological disorders among dentists has been reported. Only one study explored job satisfaction among Health Insurance Organization dentists, in Alexandria. However, job satisfaction among Ministry of Health and Population (MOHP) dentists has not been examined.

OBJECTIVES: The objective of this study was to measure the level of job satisfaction among MOHP dentists, in Alexandria and to assess the association of work environment factors as well as personal and practice-related factors to job satisfaction.

MATERIAL AND METHODS: This study was a cross sectional analytical survey conducted among dentists working in MOHP facilities, in Alexandria during a six month period from October 2019 to March 2020. A validated questionnaire modified from the Dentists Satisfaction Survey that was previously tested in Saudi Arabia was adopted. The first section was concerned with demographic and practice related data whereas the second section explored work environment factors. Multivariable stepwise linear regression analysis was performed to examine the association between total mean job satisfaction with personal/ practice related characteristics and work environment factors.

RESULTS: The level of job satisfaction was neutral (2.91 \pm 0.41$)$. Overall job satisfaction (Beta=0.437), monetary satisfaction (Beta=0.328) and personal time (Beta $=0.265$ ) reported the most significant associations with job satisfaction according to the multivariable linear regression analysis. CONCLUSIONS: This study revealed that overall job satisfaction, perception of income and personal time showed a significant impact on job satisfaction. The findings of this study would help policy makers to design plans to increase level of job satisfaction among dentists.
\end{abstract}

KEY WORDS: Professional satisfaction, Dentists, Public sector, Egypt.

RUNNING TITLE: Job satisfaction among MOHP dentists

1 Bachelor of Dental medicine and surgery 2006, Faculty of Dentistry, Alexandria University, Egypt.

2 Professor of Dental Public health, Faculty of Dentistry, Alexandria University, Egypt.

* Corresponding Author:

E-mail: emanghannam2008@gmail.com

\section{INTRODUCTION}

Dentistry has been identified as being one of the most stressful professions with increased levels of occupational factors that greatly affect physical and psychological wellbeing of dentists. Job satisfaction affects not only job productivity and performance but also contributes to better quality of life in general (1-3).Job satisfaction can be defined as individual's attitude towards their job (3).

Job satisfaction is a multidimensional construct which is influenced by three primary factors; practice related characteristics, worker characteristics and non-work factors. First, practice related characteristics which include both actual and perceived features of the job. These include work conditions, delivery of patient care, time to develop professionally, professional relations, patient relations, practice management, the professional environment, stress, income and respect. Second, personal factors which include the demographic characteristics such as age, gender, marital status and emotional status. Third, nonwork factors which are related to the quality of life, personal time and social relations (4).

Studies carried out in England (2), Staffordshire (4) and Poland (5), which examined dentists working in the public sector along with dentists having private practices and dentists working in both, concluded that total job satisfaction was attributable to respect, perception of income, delivery of care, dentist-patient relationships and professional time. The most significant predictor of dental job satisfaction was found to be the intrinsic rewards of being a dentist and the delivery of dental health services. Less satisfying aspects of dentistry included practice management and financial planning.

Findings from different European countries such as Turkey, Germany and the Netherlands reported that seeing immediate results, a focus on aesthetics and the type of social insurance highly affect job satisfaction. In addition, income level, the presence of dental auxiliaries, the number of patients examined per day as well as job autonomy were also among the significant factors related to total mean satisfaction of dentists (6-8).

Several studies, conducted in Australia in 2011 and 2016, showed that workplaces that offer job autonomy, competitive pay, flexible working hours, and minimal administrative burden may improve dentist job satisfaction $(3,9)$. In Canada, it was found that the most satisfied orthodontists where those who reported higher incomes, attended more continuing education, and employed more dental auxiliaries. In contrast, they were most dissatisfied with the threat of malpractice, level of income, demands of managing the practice, and amount of personal time (10).

Regarding developing countries, different dimensions of job satisfaction were also studied. In the Asian continent, 
particularly in India, multiple studies concluded that perception of income, professional recognition, leisure or personal time, relationship with staff and patients, job autonomy and professional development were among the factors associated with job satisfaction of dentists. The same results were emphasized in studies conducted in South Korea, China and Eastern Nepal (11-17).

In the kingdom of Saudi Arabia, studies conducted in Riyadh, Hail and Najran showed that quality of patient care, dentistpatient relation, staff performance, monetary satisfaction, professional development, personal or leisure time as well as job security are associated with job satisfaction of the dental workforce (18-20).

In Egypt, job satisfaction among practicing dentists, at different hospitals, in Suez Canal area was assessed using a modified version of the DSS. This study reported that patient relations, perception of the value of income, personal time, staff and training opportunities are important work environment factors for job satisfaction among dentists (21). Moreover, El Bayoumi (22) examined job satisfaction among the Health Insurance Organization (HIO) dentists in Alexandria, and stated that patient relations, professional environment, auxiliary staff, perception of income and work stress are factors significantly affecting job satisfaction. Although MOHP is considered the largest provider of health care services all through the country, no studies investigated job satisfaction among its dentists in Alexandria (23).

Since job satisfaction is a complex and multifaceted phenomenon, it was perceived that identification of the related factors could lead to a better strategy and policy which provide an adequate work environment for the practicing dentists. This environment would eventually improve not only the patient care but the entire dental care system (21).

In Egypt, the increasing demand for quality health care has recently focused on the appropriate work conditions for health care providers especially since the Health Sector Reform Program (HSRP). This reform program has been introduced (1997-2020) as well as the new universal health insurance system law issued in 2017 (24-26). Therefore, assessing the level of job satisfaction and its association with the work conditions, among different categories of health care providers, is required. The lack of studies conducted to explore job satisfaction among dentists, in Alexandria, particularly was the motivational factor for planning and implementing the present study. The study aimed to measure the level of total job satisfaction as well as to assess the association of personal and practice related factors along with work environment factors to job satisfaction among MOHP dentists, in Alexandria. It tested the null hypothesis that job satisfaction is not related to either work environment factors or personal factors of the dental practice.

\section{MATERIAL AND METHODS \\ Study design}

The current study was based on an analytical, cross-sectional design using a previously validated questionnaire modified from the Dentists Satisfaction Survey (DSS), tested in Saudi Arabia and presented in English language (19). Data were collected in a 6 months period (Oct. 2019- March 2020) from 356 dentists working in MOHP health units, centers and hospitals affiliated to the eight health districts, in Alexandria, namely: Montazah, East, Middle, West, Agamy, Gomrok, Borg El Arab and Ameriyah, in addition to the two specialized dental centers that report directly to the Directorate of Health Affairs of Alexandria governorate. The sample included all dentists working in MOHP facilities at the time of data collection. Each facility was visited twice in two different times of day to ensure the participation of morning and evening shifts. The total mean job satisfaction was the dependent variable and the work environment factors along with personal and practice related factors were the independent variables.

The approval of the Dental Research Ethics Committee at Faculty of Dentistry, Alexandria University was obtained. In addition, a letter from the faculty explaining the objective of the study and seeking approval was sent to the Alexandria Directorate of Health Affairs in order to gain access to the Healthcare facilities of the Ministry of Health. Furthermore, the permission of the participating dentists was obtained through a detailed explanation of the objectives of the research, in order to gain their trust and confidence as well as their full cooperation.

Participation of the dentists was on voluntary basis and a sample size of 356 dentists was clearly advised that they had the right to comply or refuse participation. Anonymousness and confidentiality of the respondents were assured and personal data were secured. Returning back the filled questionnaire was considered as an implied consent with no need for further written consent.

A list of the total number of dentists working in the different health districts of Alexandria governorate was obtained from the directorate of health affairs. The list initially contained 1970 dentists who were working, in 2019. The sample size was calculated based on a study aimed to measure the level of job satisfaction and the work factors associated with it among practicing dentists in Suez Canal governorates hospitals. Fahim AE (2013) reported average 36.86\% satisfied dentists among his sample (21). A sample size of 356 dentists is the enough required sample $80 \%$ power and at a significance level 95\% (accepted alpha error of 0.05) (27).

The questionnaire consisted of two main sections. The first was concerned with the demographic, personal and practice related variables of the participants such as age, gender, qualification, marital status, specialty, years of practice, average number of working hours per week, presence of dental assistant and having a private practice. The second section consisted of 30 items formulated as statements of opinion and the responses were scaled on a 5 point likert scale as follows; strongly disagree $=1$, disagree $=2$, neutral $=3$, agree $=4$, strongly agree $=5$. The first seven items to measure the factor of overall professional satisfaction with statements inquiring if dentistry is meeting the current hopes and expectations of the dentist and whether dentistry is the place whereby the dentist can make the best contribution, or if helshe desires to leave his job or would select dentistry again. Also, a query if helshe appears to be more satisfied with dentistry than he/she really is or if they were extremely satisfied with the career. The remainder 23 items measure 7 work environment factors that included: income level in 5 items (if it fulfills his/her family needs compared to other dentists), personal time in 3 items (whether the dentist is having enough time for personal life and leisure activities or not), professional development 
time in 4 items (the dentist is having sufficient time to improve clinical skills and to be updated about latest advances in the field), staff performance in 3 items (work performance quality of the auxiliary personnel as a team), dentist-patient relation in 4 items (whether the dentist is enjoying interacting with patients and helping them or not), and quality of care in 3 items (if the dentist is having the skills required to deal with dental problems and to provide quality care to the patients). The seventh factor namely physical work environment included 1 item asking about the working conditions (heating, ventilation, lighting, etc...) of the job. This item was added from the Minnesota Satisfaction Questionnaire (MSQ) (28).Therefore, the questionnaire was revalidated where internal consistency was assessed on a subset of 20 individuals randomly chosen, whose results were included subsequently in the final analysis. The average measure ICC was 0.83 with a $95 \%$ confidence interval from 0.68 to $0.93(\mathrm{P}<0.0001)$, indicating a high degree of internal consistency. In addition, Content validity was examined by six staff members of the faculty of dentistry in Alexandria University. The experts evaluated every item in the questionnaire for validity, the content validity index (CVI) was 0.85 and the content validity ratio (CVR) was 0.75 denoting very high score.

Of the 30 items, 13 items are negatively worded, where a higher score indicates a lower job satisfaction. The responses to these negatively worded items were reverse coded during data entry so that a higher score will indicate a higher job satisfaction.

The total satisfaction score was calculated for the sum of all the eight satisfaction dimensions together then averaged to obtain the mean total satisfaction for each subgroup of participants in association with different studied variables as age, gender, qualification, marital status, specialty, years of practice, average number of working hours per week, presence of dental assistant as well as having a private practice.

The mean values for each factor were divided into three categories (dissatisfied=1.0-2.5, (neutral $=2.6$ to $<3.54$, and satisfied= 3.6to 5.0), in order to obtain the distribution of overall job satisfaction dimension and other work environment factors.

\section{Statistical analysis}

The 30 statements were grouped into eight dimensions of job satisfaction namely, overall satisfaction, quality of care, dentist-patient relations, staff performance, professional development time, monetary satisfaction, personal time and physical work environment.

Each item was given a score according to dentists selection as follows; strongly disagree $=1$, disagree $=2$, neutral $=3$, agree $=$ 4 , strongly agree $=5$, so that a higher score will indicate a higher job satisfaction. Responses were then averaged for all respondents to determine the mean score of each satisfaction dimension.

Data were entered into an SPSS file version 20.0. (Armonk, NY: IBM Corp). Descriptive statistics were calculated as frequencies and percentages for qualitative variables while means and standard deviation for quantitative variables. Significance of the obtained results was judged at the $5 \%$ level.

Student t-test as well as F-test (ANOVA) were used to detect the relation between total mean job satisfaction and personal / practice related factors.
A multivariable stepwise linear regression analysis was performed to examine the association between total mean job satisfaction with personal/ practice related and work environment factors. The total mean job satisfaction was used as the dependent outcome variable and the other variables were used as independent predictor variables. A $p \leq 0.05$ was used as a statistical significance level.

\section{RESULTS}

Out of the 400 questionnaires distributed among the current study participants, 361 questionnaires were answered, resulting in a response rate of $90.25 \%$. Table (1) shows the description of socio-demographic and practice related data of the study sample. The greatest number of respondents was females (73.1\%). About (42.7\%) of the participants were between 30 to 39 years, with a mean age of $35.07 \pm 9.83$. More than half (58.2\%) of the participants were married. Regarding practice related and work characteristics of the respondents, the greatest number of respondents had a bachelor degree (69.3\%) and were general practitioners (69.3\%). Around half of the participants (47.4\%) were practicing dentistry for 10 years and more. Around $79.2 \%$ of them work fulltime (36hrs/week) while $20.8 \%$ work part-time (18hrs/week). The majority (80.1\%) had dental assistant in the clinic and about $60.4 \%$ did not have a private practice. Most of the participants (70.6\%) worked in family health units and centers, $13.9 \%$ work in Ministry of Health hospitals whereas $15.5 \%$ work in dental research centers (Smouha Research center and Moharam Bek research center)

Table (2) shows the mean satisfaction scores and distribution of satisfaction levels for the different satisfaction dimensions. The respondents gave the highest score to the" relation with their patients"(3.49 \pm 0.59).The" staff performance" and "quality of care" items showed the next highest mean satisfaction scores (3.29 \pm 0.68 and $3.11 \pm 0.66$, respectively). The perception of "income" and "physical work environment" revealed the lowest mean satisfaction scores $(2.13 \pm 0.74$ and $2.38 \pm 1.19$, respectively). The total mean satisfaction score was $2.91 \pm 0.41$.

Data in table (3) show the relation between total dentists' job satisfaction mean score and socio-demographic as well as practice related variables. The difference between job satisfaction scores among age groups was statistically significant $(\mathrm{P}<0.001)$.The highest satisfaction score was reported by respondents between 40 to 50 years of age (3.12 \pm 0.44 ) while the lowest satisfaction score was reported by younger dentists aging between 30 to 39 years (2.82 \pm 0.40$)$. Regarding practice related characteristics of the respondents, statistically significant differences existed between total job satisfaction score and dentist's qualification, years of practice and presence of dental assistant $(\mathrm{P}=0.005, \mathrm{P}<0.001$, $<0.001$ and respectively).The highest total satisfaction scores were reported by freshly employed dentists who have been practicing dentistry between 1 and 3 years $(2.97 \pm 0.35)$ as well as dentists who received diploma as the highest scientific degree (3.07 \pm 0.41$)$.

The multivariable stepwise linear regression best fitting model (table 4) showed that Overall job satisfaction had the most significant impact on dentists' job satisfaction (Beta $=0.437$, $\mathrm{P}<0.001)$. Monetary satisfaction came in the second place (Beta=0.328, $\mathrm{P}<0.001$ ). Other significant factors included 
personal time, professional development time, dentist-patient relation, staff performance, quality of care and years of practice.

Table (1): Percentage distribution of study sample according to socio-demographic and practice related characteristics of respondents. $(\mathrm{n}=361)$

\begin{tabular}{|c|c|c|}
\hline Personal data & No. & $\%$ \\
\hline Age & & \\
\hline$<30$ & 124 & 34.3 \\
\hline $30-39$ & 154 & 42.7 \\
\hline $40-50$ & 33 & 9.1 \\
\hline$>50$ & 50 & 13.9 \\
\hline Min. - Max. & \multicolumn{2}{|c|}{$\begin{array}{c}23.0-59.0 \\
35.07 \pm 9.83\end{array}$} \\
\hline \multicolumn{3}{|l|}{ Sex } \\
\hline Male & 97 & 26.9 \\
\hline Female & 264 & 73.1 \\
\hline \multicolumn{3}{|l|}{ Qualification } \\
\hline BDS & 250 & 69.3 \\
\hline Diploma & 57 & 15.8 \\
\hline Master + PhD & & \\
\hline \multicolumn{3}{|l|}{ Marital status } \\
\hline Single & 137 & 38.0 \\
\hline Married & 210 & 58.2 \\
\hline Divorced & 10 & 2.8 \\
\hline Widower & 4 & 1.1 \\
\hline \multicolumn{3}{|l|}{ Specialty } \\
\hline GP & 250 & 69.3 \\
\hline Others & 111 & 30.7 \\
\hline \multirow{2}{*}{\multicolumn{3}{|c|}{ Years of practice }} \\
\hline & & \\
\hline $1-3$ & 89 & 24.7 \\
\hline $3-10$ & 101 & 28.0 \\
\hline 10 and more & 171 & 47.4 \\
\hline \multicolumn{3}{|l|}{$\begin{array}{l}\text { No. of working } \\
\text { hrs/week }\end{array}$} \\
\hline Part-time 18 hours & 75 & 20.8 \\
\hline Fulltime 36 hours & 286 & 79.2 \\
\hline $\begin{array}{l}\text { Min. - Max. } \\
\text { Mean + SD }\end{array}$ & & \\
\hline \multicolumn{3}{|l|}{$\begin{array}{l}\text { Presence of dental } \\
\text { assistant }\end{array}$} \\
\hline No & 72 & 19.9 \\
\hline Yes & 289 & 80.1 \\
\hline \multicolumn{3}{|l|}{$\begin{array}{l}\text { Having a private } \\
\text { practice }\end{array}$} \\
\hline No & 218 & 60.4 \\
\hline tes & 143 & 39.6 \\
\hline \multicolumn{3}{|l|}{ Type of facility } \\
\hline $\begin{array}{l}\text { Family health units } \\
\text { and centers }\end{array}$ & 255 & 70.6 \\
\hline Hospitals & 50 & 13.9 \\
\hline $\begin{array}{l}\text { Dental research } \\
\text { centers }\end{array}$ & 56 & 15.5 \\
\hline
\end{tabular}

Table (2): Mean satisfaction score and distribution of satisfaction levels for study participants in different satisfaction dimensions.

\begin{tabular}{|l|l|l|}
\hline & & Satisfaction level \\
\hline
\end{tabular}

\begin{tabular}{|c|c|c|c|c|c|c|c|}
\hline \multirow{2}{*}{$\begin{array}{l}\text { Dentist } \\
\text { satisfaction }\end{array}$} & \multirow{2}{*}{$\begin{array}{l}\text { Satisfacti } \\
\text { on score }\end{array}$} & \multicolumn{2}{|c|}{$\begin{array}{r}\text { Satisfied } \\
(3.6-5.0)\end{array}$} & \multicolumn{2}{|c|}{$\begin{array}{c}\text { Neutral } \\
(2.60- \\
3.59)\end{array}$} & \multicolumn{2}{|c|}{$\begin{array}{c}\text { Dissatisfie } \\
\text { d } \\
(1.0-2.5)\end{array}$} \\
\hline & & No & $\%$ & No & $\%$ & No & $\%$ \\
\hline Overall job & $3.03 \pm 0.75$ & $\begin{array}{c}12 \\
1\end{array}$ & $\begin{array}{c}33 . \\
5\end{array}$ & $\begin{array}{c}15 \\
7 \\
\end{array}$ & $\begin{array}{c}43 . \\
5\end{array}$ & 83 & 23.0 \\
\hline $\begin{array}{l}\text { Quality of } \\
\text { care }\end{array}$ & $3.11 \pm 0.66$ & $\begin{array}{c}10 \\
7\end{array}$ & $\begin{array}{c}29 . \\
6\end{array}$ & $\begin{array}{c}20 \\
1\end{array}$ & $\begin{array}{c}55 . \\
7\end{array}$ & 53 & 14.7 \\
\hline $\begin{array}{l}\text { Dentist patient } \\
\text { relations }\end{array}$ & $3.49 \pm 0.59$ & $\begin{array}{c}22 \\
1\end{array}$ & $\begin{array}{c}61 . \\
2\end{array}$ & $\begin{array}{c}11 \\
0\end{array}$ & $\begin{array}{c}30 . \\
5\end{array}$ & 30 & 8.3 \\
\hline \begin{tabular}{l|} 
Staff \\
performance
\end{tabular} & $3.29 \pm 0.68$ & $\begin{array}{c}12 \\
7 \\
\end{array}$ & $\begin{array}{c}35 . \\
2\end{array}$ & $\begin{array}{c}19 \\
3\end{array}$ & $\begin{array}{c}53 . \\
5\end{array}$ & 41 & 11.4 \\
\hline $\begin{array}{l}\text { Professional } \\
\text { development } \\
\text { time }\end{array}$ & $2.89 \pm 0.77$ & 98 & $\begin{array}{c}27 . \\
1\end{array}$ & $\begin{array}{c}12 \\
7\end{array}$ & $\begin{array}{c}35 . \\
2\end{array}$ & $\begin{array}{c}13 \\
6\end{array}$ & 37.7 \\
\hline $\begin{array}{l}\text { Monetary } \\
\text { satisfaction }\end{array}$ & $2.13 \pm 0.74$ & 19 & 5.3 & 92 & $\begin{array}{c}25 . \\
5\end{array}$ & $\begin{array}{c}25 \\
0\end{array}$ & 69.3 \\
\hline $\begin{array}{l}\text { Personal } \\
\text { time }\end{array}$ & $2.80 \pm 0.99$ & $\begin{array}{c}10 \\
9\end{array}$ & $\begin{array}{c}30 . \\
2\end{array}$ & 92 & $\begin{array}{c}25 . \\
5\end{array}$ & $\begin{array}{c}16 \\
0\end{array}$ & 44.3 \\
\hline $\begin{array}{l}\text { Physical } \\
\text { work } \\
\text { environment }\end{array}$ & $2.38 \pm 1.19$ & 74 & $\begin{array}{c}20 . \\
5\end{array}$ & 67 & $\begin{array}{c}18 . \\
6\end{array}$ & $\begin{array}{c}22 \\
0\end{array}$ & 60.9 \\
\hline $\begin{array}{l}\text { Total mean } \\
\text { satisfaction } \\
\text { score }\end{array}$ & $2.91 \pm 0.41$ & 26 & 7.2 & $\begin{array}{c}27 \\
8\end{array}$ & $\begin{array}{r}77 . \\
0\end{array}$ & 57 & 15.8 \\
\hline
\end{tabular}

Table (3): Relation between total mean job satisfaction scores and personal and practice related factors.

\begin{tabular}{|c|c|c|c|c|}
\hline \multicolumn{2}{|c|}{ Personal data } & $\begin{array}{c}\text { Total mean } \\
\text { job } \\
\text { satisfaction } \\
\text { score }\end{array}$ & $\begin{array}{l}\text { Test of } \\
\text { Sig. }\end{array}$ & $\mathbf{p}$ \\
\hline Age & $\begin{array}{c}<30 \\
30-39 \\
40-50 \\
>50\end{array}$ & $\begin{array}{l}2.93 \pm 0.39 \\
2.82 \pm 0.40 \\
3.12 \pm 0.44 \\
3.04 \pm 0.38\end{array}$ & $\mathrm{~F}=7.849 *$ & $<0.001^{*}$ \\
\hline Sex & $\begin{array}{c}\text { Male } \\
\text { Female }\end{array}$ & $\begin{array}{l}2.95 \pm 0.48 \\
2.90 \pm 0.38\end{array}$ & $t=0.924$ & 0.357 \\
\hline Qualification & $\begin{array}{c}\text { BDS } \\
\text { Diploma } \\
\text { Master + PhD }\end{array}$ & $\begin{array}{l}2.88 \pm 0.38 \\
3.07 \pm 0.41 \\
2.92 \pm 0.50\end{array}$ & $=5.352 *$ & $0.005^{*}$ \\
\hline Marital status & $\begin{array}{c}\text { Single } \\
\text { Married } \\
\text { Divorced } \\
\text { Widower } \\
\end{array}$ & $\begin{array}{l}2.92 \pm 0.41 \\
2.90 \pm 0.40 \\
3.04 \pm 0.61 \\
3.07 \pm 0.63\end{array}$ & $F=0.644$ & 0.587 \\
\hline Specialty & $\begin{array}{c}\text { GP } \\
\text { Others (specialist) }\end{array}$ & $\begin{array}{l}2.88 \pm 0.37 \\
2.98 \pm 0.48\end{array}$ & $\mathrm{t}=1.956$ & 0.051 \\
\hline Years of practice & \begin{tabular}{|c|}
$1-3$ \\
$3-10$ \\
10 and more \\
\end{tabular} & $\begin{array}{l}2.97 \pm 0.35 \\
2.78 \pm 0.42 \\
2.96 \pm 0.42 \\
\end{array}$ & $\mathrm{~F}=8.051^{*}$ & $<0.001^{*}$ \\
\hline No. hours/week & $\begin{array}{l}\text { Part-time } 18 \text { hours } \\
\text { Fulltime } 36 \text { hours }\end{array}$ & $\begin{array}{l}2.98 \pm 0.36 \\
2.90 \pm 0.42\end{array}$ & $\mathrm{t}=1.618$ & 0.107 \\
\hline $\begin{array}{l}\text { Presence of dental } \\
\text { assistant }\end{array}$ & $\begin{array}{l}\text { No } \\
\text { Yes }\end{array}$ & $\begin{array}{l}2.73 \pm 0.44 \\
2.96 \pm 0.39 \\
\end{array}$ & $\mathrm{t}=4.316^{*}$ & $<0.001^{*}$ \\
\hline $\begin{array}{l}\text { Having private } \\
\text { practice }\end{array}$ & $\begin{array}{l}\text { No } \\
\text { Yes }\end{array}$ & $\begin{array}{l}2.89 \pm 0.41 \\
2.95 \pm 0.41\end{array}$ & $t=1.462$ & 0.145 \\
\hline Гуре of facility & $\begin{array}{c}\text { Family health units } \\
\text { and centers } \\
\text { Hospitals } \\
\text { Dental research } \\
\text { centers }\end{array}$ & $\begin{array}{l}2.92 \pm 0.40 \\
2.95 \pm 0.50 \\
2.87 \pm 0.38\end{array}$ & $\mathrm{~F}=0.591$ & 0.554 \\
\hline
\end{tabular}


Table (4): Multivariable stepwise linear regression for factors related to total mean job satisfaction score

\begin{tabular}{|c|c|c|c|c|c|}
\hline & B & SE & Beta & $\mathbf{t}$ & $\mathbf{p}$ \\
\hline (Constant) & 0.006 & 0.015 & & 0.367 & 0.714 \\
\hline Overall job & 0.239 & 0.003 & 0.437 & $83.721^{*}$ & $<0.001^{*}$ \\
\hline Personal time & 0.109 & 0.002 & 0.265 & $52.123^{*}$ & $<0.001^{*}$ \\
\hline $\begin{array}{l}\text { Monetary } \\
\text { satisfaction }\end{array}$ & 0.182 & 0.003 & 0.328 & $67.056^{*}$ & $<0.001^{*}$ \\
\hline $\begin{array}{l}\text { Dentist patient } \\
\text { relations }\end{array}$ & 0.129 & 0.004 & 0.184 & $35.414^{*}$ & $<0.001^{*}$ \\
\hline \begin{tabular}{|l|} 
Professional \\
development time
\end{tabular} & 0.132 & 0.003 & 0.247 & $47.924^{*}$ & $<0.001^{*}$ \\
\hline \begin{tabular}{|l|} 
Staff \\
performance
\end{tabular} & 0.104 & 0.003 & 0.172 & $33.365^{*}$ & $<0.001^{*}$ \\
\hline Quality of care & 0.102 & 0.003 & 0.162 & $31.642^{*}$ & $<0.001^{*}$ \\
\hline Year of practice & 0.057 & 0.001 & 0.010 & $2.057^{*}$ & $0.040^{*}$ \\
\hline \multicolumn{6}{|c|}{$\begin{aligned} R^{2}=0.992, \text { adjusted } R^{2}= & 0.992, \\
& p<0.001^{*}\end{aligned}$} \\
\hline
\end{tabular}

F, $\quad \mathrm{p}$ : $\mathrm{f}$ and $\mathrm{p}$ values for the model

$\mathrm{R}^{2}$ : Coefficient of determination

$\mathrm{R}$ : coefficient of regression

B: Unstandardized Coefficients

SE: Estimates Standard errorBeta: Standardized Coefficients

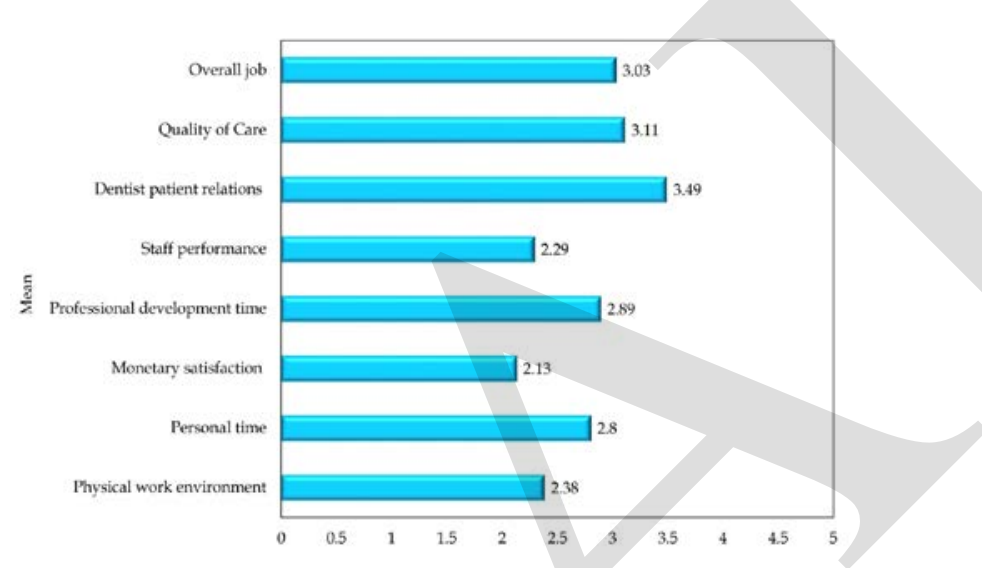

Figure (1): Mean satisfaction scores of the participants in the different dimensions of dentists' job satisfaction.

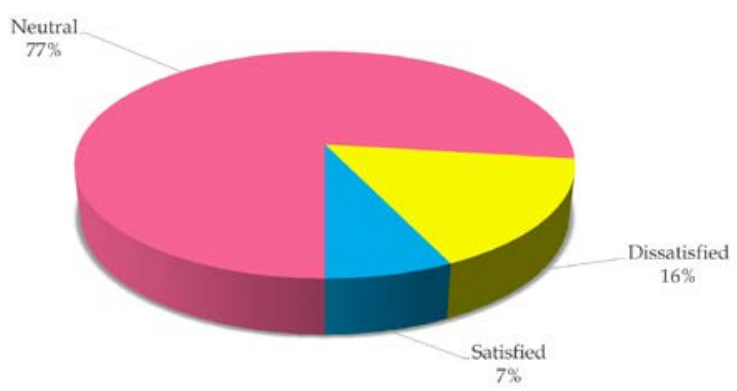

Figure (2): Distribution of the participants according to the total mean job satisfaction.

\section{DISCUSSION}

The total mean job satisfaction score of the participating dentists was $2.91 \pm 0.41$ out of 5 denoting neutral level of job satisfaction. This might be explained by the fact that dentists working in the public sector are constrained by what the public system can afford as salaries or incentives for dentists as well as what it can provide of the facilities and resources for the different types and technologies of dental treatment, which compromises their ability to practice a full range of dentistry. In addition, the public healthcare system tends to focus on improving patient's and population's experience and health while the focus on healthcare providers often gets lost among the urgency of providing care and reacting to external demands $(3,30)$.This finding is comparable with those working in the National Guard Health Affairs (NGHA), in Saudi Arabia (20), in the Health Insurance Organization in Alexandria (22), in the Suez Canal area in Egypt (21). On the other hand, the total mean job satisfaction score of this study was lower than that of Chinese dentists (3.28 out of 5) (17) as well as Saudi dentists working in Hail region (3.35out of 5) (19).The higher score among Chinese dentists might be due to the ongoing reform of China's healthcare system. Moreover, the income of Chinese dentists is in the upper third of all occupations and dentists can fulfill a variety of leadership positions.

The highest satisfaction mean score was related to dentistpatient relation, which is again in agreement with the dentists working in the HIO in Alexandria (22) as well as dentists working in the Suez Canal area (21). Gadallah et al (31) also reported that relationship with patients seems to be the most important satisfaction factor for Egyptian physicians. The compassionate nature of health care professionals, in general, and of dentists with the interactive nature of their profession, might explain this finding. Australian dentists (3) as well as Malaysian dental therapists (32) also reported the highest satisfaction mean score for dentist-patient relation dimension. Staff performance dimension reported the second highest mean satisfaction score among the participating dentists in this study. This finding is consistent with results of Fahim (21) who reported that dentists working in the Suez Canal area in Egypt ranked the staff performance dimension as the second highest mean score. The concept of team work is considered an important aspect in dentistry, with growing recognition of the role of all team members in patient care and treatment. Dental auxiliaries are important members of the dental team and enhance the efficiency of the delivery of dental care as they are responsible for infection control, preparing patients for treatment, and providing help during dental procedures $(28,33-35)$.

The third highest mean satisfaction score among the current study participants was reported for quality of care dimension. Similarly, quality of care dimension reported the third highest mean satisfaction score among dentists working in the Suez Canal area in Egypt (21). Dentists working in the HIO in Alexandria also reported a high mean satisfaction score for opportunity to deliver quality services (22). The quality of healthcare services in MOHP facilities has considerably improved since the implementation of the Health Sector Reform Program (HSRP), where adequate equipment and 
essential drugs became available (31). This might explain the satisfaction of the current study participants with the quality of services they provide to patients. Similar findings were reported among Saudi dentists in Hail region, Malaysian dental therapists as well as dentists of the National Guard Health Affairs in Riyadh (20,21,36).

Perception of income or monetary satisfaction dimension showed the lowest mean satisfaction score among most of the current study participants. Although the Health Sector Reform Program (HSRP) was launched, in Egypt, in 1997, several challenges still face the Ministry of Health and Population (MOHP) to achieve the goals of the reform program. Among these goals should be the upgrading of dentists'salaries and incentives and improving their economic situation, while the limited resources of the ministry probably hinder the achievement of this goal. The current study result is consistent with El-Bayoumi (22) who revealed that dentists working in the Health Insurance Organization (HIO), in Alexandria, also reported the lowest satisfaction mean score for perception of income dimension, where the majority of dentists (83.7\%) were dissatisfied with this aspect. Dentists working in the Suez Canal Area in Egypt reported a higher satisfaction mean score for perception of income, where almost half (47.7\%) of the participants expressed neutral satisfaction for this aspect (21). On the other hand, the present result is considerably lower than that reported by South Korean dentists (11), Saudi dentists in Hail region (19), Indian dentists in Sirkakulam (37) and Australian dentists (3). This might be also attributed to the increasing cost of life in Egypt accompanying the economic crisis and reform (23).

A statistically significant difference was observed among the different age groups regarding the total mean satisfaction ( $\mathrm{P}$ $<0.001$ ), where the highest mean score was reported for dentists between $40-50$ years of age while younger dentists between 30-39 years of age reported the lowest mean score. Similar results were reported, in Egypt, by El-Bayoumi (22) and Fahim (21). Older dentists might be more satisfied because of promotions and acquiring more desirable positions within their organizations. On the other hand, Kobza and Syrkiewicz- ' Switała (5) reported that the level of job satisfaction among dentists, in Poland, decreased with age; the group with the lowest level of satisfaction is represented by the oldest dentists, over 60 years of age. This was explained by the cumulative negative effect of the various psychological and physiological stressors in the working environment of dentists as well as the expected reduction of financial resources upon retirement. All this might contribute to lowering job satisfaction.

Meanwhile, dentists with diploma, as the highest degree, reported the highest total mean job satisfaction score. This may be attributed to them having the first postgraduate degree which denoted them a level of satisfaction and ambition to provide better services for their patients (39). While the lower degree of satisfaction expressed by Master's degree holders may reflect their higher demands for social recognition, better working conditions, better quality services as well as higher monetary expectations. Dentists working in the HIO, in Alexandria, reported similar results (22). Dentists and dental assistants with postgraduate qualification also reported higher job satisfaction mean scores in Brazil, Sirkakulam (India) as well as Ghaziabad (India) $(14,37,38)$.
Dentists working with dental assistants reported higher mean job satisfaction score than those who don't. Presence of dental assistants was found to enhance job satisfaction among dentists according to studies conducted in South Korea as well as Germany and this was explained by the assumption that dental assistants reduce the job demands and responsibilities on dentists, and provide more convenient working environment $(8,11)$.

Freshly employed dentists (1-3 years of practice) were also more satisfied ( $\mathrm{t}$ because young employees may feel satisfied due to their limited experience about the labor market against which their own work is judged. As they learn with some years of experience, they are able to better judge the conditions of their work, thus, satisfaction drops in the middle age (22).

The regression model revealed that overall job satisfaction and perception of income were the most significant predictors of job satisfaction among the current study participants. Similar results were reported in Suez Canal area (Egypt) (21), Hail region (KSA) (19) and China (17).

Based on the current study results, the null hypothesis that job satisfaction is not affected by work environment and other factors among the Ministry of Health and Population (MOHP) dentists can be safely rejected.

Limitations of the study include the study being based on a cross sectional survey, thus the causality of any associations is not strongly proved. In addition, the generalizability of the study is limited as the sample only included dentists working in the MOHP and did not include dentists working in other governmental organizations such as (HIO), Police and Military hospitals as well as dentists working in the private sector. Nevertheless, the current study helped in providing an insight into understanding the different personal, practice related as well as work environment factors influencing job satisfaction among dentists of MOHP in Alexandria, where the considerably high response rate (90.25\%) might be considered as point of strength.

\section{CONCLUSIONS}

In view of the results of the present study it is concluded that job satisfaction was neutral among most of the participating dentists, the highest satisfaction scores were related to dentist patient relationship, cooperative staff and quality of care delivered whereas low income, inadequate physical environment and lack of personal time were given the least satisfaction scores. Significantly higher total job satisfaction scores were noticed among older dentists (40-50 years of age), dentists with Diploma as their highest degree, freshly employed dentists with only 1-3 years of experience as well as dentists working with dental assistants. It can be recommended that policies defining the standards of dental care quality, improving dentists' compensation packages and enhancing appropriate working environment are suggested in order to increase levels of job satisfaction among dentists. Further research exploring job satisfaction of Egyptian dentists might build upon the current study by including larger sample size, involving other healthcare providing facilities and different measuring tools of job satisfaction.

\section{CONFLICT OF INTEREST}

The authors declare that they have no conflicts of interest 
FUNDIND STATMENT: The authors received no specific funding for this work

\section{REFERENCES}

1. Puriene A, Petrauskiene J, Janulyte V, Balciuniene I. Factors related to job satisfaction among Lithuanian dentists. Stomatologija. 2007;9:109-13.

2. Harris R V, Ashcroft A, Burnside G, Dancer JM, Smith D, Grieveson B. Summary of: Facets of job satisfaction of dental practitioners working in different organisational settings in England. Br Dent J. 2008;204:16-7.

3. Luzzi L, Spencer AJ. Job satisfaction of the oral health labour force in Australia. Aust Dent J. 2011;56:23-32.

4. Gilmour J, Stewardson DA, Shugars DA, Burke FJT. An assessment of career satisfaction among a group of general dental practitioners in Staffordshire. $\mathrm{Br}$ Dent J. 2005;198:701-4.

5. Kobza J, Syrkiewicz-Świtała M. Job satisfaction and its related factors among dentists: A cross-sectional study. Work. 2018;60:357-63.

6. Gorter RC, Brake J, Eijkman M, Hoogstraten J. Job resources in Dutch dental practice. Int Dent J. 2006;56:228.

7. Gorter RC, Te Brake HJ, Hoogstraten J, Eijkman MA. Positive engagement and job resources in dental practice. Community Dent Oral Epidemiol. 2008;36:47-54.

8. Goetz K, Campbell SM, Broge B, Dörfer CE, Brodowski $\mathrm{M}$, Szecsenyi J. The impact of intrinsic and extrinsic factors on the job satisfaction of dentists. Community Dent Oral Epidemiol. 2012;40:474-80.

9. Balasubramanian M, Spencer AJ, Short SD, Watkins K, Chrisopoulos S, Brennan DS. Job satisfaction among 'migrant dentists' in Australia: implications for dentist migration and workforce policy. Aust Dent J. 2016;61:17482.

10. Roth SF, Heo G, Varnhagen C, Glover KE, Major PW. Job satisfaction among Canadian orthodontists. Am J Orthod Dentofac Orthop. 2003;123:695-700.

11. Jeong SH, Chung JK, Choi YH, Sohn W, Song KB. Factors related to job satisfaction among South Korean dentists. Community Dent Oral Epidemiol. 2006;34:460-6.

12. Jain M, Mathur A, Joshi S, Goklani P, Kothari B, Prabu D, et al. Job Satisfaction Assessment Among Dentists And Dental Auxiliaries In India. Int J Dent Sci 2008;7:1-8.

13. Bhagat Tk, Shrestha A, Choudhary A, Sherchan S, Dahal S, Yadav M. Job satisfaction among dentists of eastern Nepal - a pilot study. JNDA. 2014;14:2-5.

14. Pandita V, Patthi B, Singla A, Singh S, Malhi R, Vashishtha V. Professional satisfaction among dental practitioners in Ghaziabad city. J Indian Assoc Public Health Dent. 2015;13:2015-8.

15. Sudhakar Kaipa, Siva Kumar Pydi RVSK, Kumar, Gomasani Srinivasulu, Venkata Rajesh Kumar Darsi MS. Career satisfaction among dental practitioners in Srikakulam, India. J Int Soc Prev Community Dent. 2015;5:40-6.

16. Dwivedi A, Purohit BM, Bhambhal A. Exploring Factors Influencing Job Satisfaction and Its Bearing on Performance among Dentists in Central India. J of Health,
Med. And Nursing. 2015;21:16-22.

17. Cui X, Dunning D, An N. Satisfaction among early and mid-career dentists in a metropolitan dental hospital in China. J Healthc Leadersh. 2017;9:35-45.

18. Al-Smadi MS, Qblan YM. Assessment of Job Satisfaction among Faculty Members and its Relationship With Some Variables in Najran University. J Educ Pract. 2015;6:117-23.

19. Aljanakh M. Job satisfaction among saudi public sector dentists in hail region. Pak Oral Dental J. 2017;37:123-7.

20. Hamasha AA, Alturki A, Alghofaili N, Alhomaied A, Alsanee F, Aljaghwani F, et al. Predictors and Level of Job Satisfaction among the Dental Workforce in National Guard Health Affairs. J Int Soc Prev Community Dent. 2019;9:89-93.

21. Fahim AE. Predictors of job satisfaction among practicing dentists at hospitals in Suez Canal Area, Egypt. Int J Occup Med Environ Health. 2013;26:49-57.

22. El-Bayoumi MA. Job satisfaction of dentists in the health insurance organization facilities in Alexandria. M.Sc. Thesis. Pediatric Dentistry and Dental Public Health Department, faculty of dentistry, Alexandria University. Egypt. 2013.

23. Gericke A, Britain K, Elmahdawy M, Elsisi G. Health System in Egypt. In: Ginneken E, Busse R (eds). Health care Systems and policies, Health Services Research. New York, NY: Springer; 2018.

24. Al Bahnasy R, Mohamed O, El-Shazly H, Abdel-Azeem A, Khedr R. The successes and the challenges of Egyptian Health Sector Reform Program. Menoufia Med J. 2016;29:979-83.

25. Mathauer I, Khalifa AY, Mataria A. Implementing the Universal Health Insurance Law of Egypt. World Health organization. 2019.

Available

at: https://apps.who.int/iris/bitstream/handle/10665/311781/ WHO-UHC-HGF-HF-CaseStudy-19.13-eng.pdf

26. Rafla S. Cronicon EC Cardiology Observational Study Review Article: One Million Wellness Egyptian Project. EC Cardiology. 2019;6.12:1-5.

27. Charan JBT. How to calculate sample size for different study designs in medical research. Indian J Psychol Med. 2013;35:121-6.

28. Weiss DJ, Dawis RV, England GW. Lofquist LH. Manual for the Minnesota Satisfaction Questionnaire. Minnesota: University of Minnesota; 1967.

29. Chevalier S, Fouquereau E, Bénichoux F, Colombat P. Beyond working conditions, psychosocial predictors of job satisfaction, and work engagement among French dentists and dental assistants. J Appl Biobehav Res. 2018;24:1-10.

30. Appelbaum NP, Lee N, Amendola M, Dodson K, Kaplan B. Surgical resident burnout and job satisfaction: the role of workplace climate and perceived support. J Surg Res. 2019;234:20-5.

31.Gadallah MA, Allam MF, Ahmed AMA, El-Shabrawy EM. Are patients and healthcare providers satisfied with health sector reform implemented in family health centres? Qual Saf Heal Care. 2010;19:1-5.

32. Bakar AA, Nor NM, Ab-Murat N, Jaafar N. Job satisfaction and perceived future roles of Malaysian dental 
therapists : findings from a national survey. Int J Dent Hyg 2015;13:199-205.

33. Al Jazairy YH, Halawany HS, Hussainan NA, Maflehi NA, Abraham NB, Jacob V. Factors affecting job satisfaction and their correlation with educational standards among dental assistants. Ind Health 2014;52:324-33.

34. Goetz K, Hasse P, Campbell SM, Berger S, Dörfer CE, Hahn K, et al. Evaluation of job satisfaction and working atmosphere of dental nurses in Germany. Community Dent Oral Epidemiol. 2016;44:24-31.

35. Osman BM, Elshara HM, Elkarmalawy E. Oral and dental nursing care knowledge and practice among nurses working at primary dental clinic: a survey study. IJRANSS. 2018; 6:67-78.
36. Abu Bakar A, Mohd Nor NA, Ab-Murat N, Jaafar N. Job satisfaction and perceived future roles of Malaysian dental therapists: Findings from a national survey. Int J Dent Hyg. 2015;13:199-205.

37. Kaipa S, Pydi SK, Krishna Kumar RV, Srinivasulu G, Darsi VR, Sode M. Career satisfaction among dental practitioners in Srikakulam, India. J Int Soc Prev Community Dent. 2015;5:40-6.

38. Loretto NRM, Caldas A de F, Coelho Junior LGT de M. Job satisfaction among dental assistants in Brazil. Braz Dent J. 2013;24:53-8. 